\title{
Life, Liberty, and the Pursuit of Quality-adjusted Life-Years after Pancreatic Cancer Surgery
}

\author{
David B. Adams
}

Published online: 20 January 2011

(c) Société Internationale de Chirurgie 2011

The citizens of the United States hold in their core consciousness the beliefs formulated by the men who signed the Declaration of Independence in Philadelphia in July 1776: "We hold these truths to be self-evident, that all men are created equal, that they are endowed by their Creator with certain unalienable Rights, that among these are Life, Liberty and the pursuit of Happiness." What happens, however, when my pursuit of happiness interferes with your liberty? A large step is taken in a human being's moral life when it becomes clear that the universe is not in harmony, that there exist irremovable conflicts of values that are an intrinsic element in human life. The inevitable clash that comes when my liberty interferes with your pursuit of happiness parallels the conflict in medical ethics when a patient's autonomy conflicts with fairness and medical justice. It is commonplace, to paraphrase the British philosopher Isaiah Berlin [1], that neither equal access to medical care nor efficient, quality health care is compatible with more than a modicum of individual autonomy; that justice and compassion, public and private responsibilities, the demands of the sick individual and the resources of society can conflict harshly one with another.

Moral medical values that are equally valid become incompatible in our daily hospital lives and come into conflict in ways that admit no easy resolution. Like the self-evident truths of the Declaration of Independence, the three cardinal principles of medical ethics, non-malfeasance, justice, and autonomy, often lead to a conflict between the individual and society. How can society justify a patient's wish to have expensive and risky medical

D. B. Adams $(\bowtie)$

Department of Surgery, Medical University of South Carolina, Charleston, SC, USA

e-mail: adamsdav@musc.edu treatment for an illness that fails to provide cost-effective quality-of-life? Must we withdraw expensive treatment for pancreatic cancer when the benefits, though positive, are small? But somehow and in some way it must be possible that thinking people of good will can find compatibility in what is valued in pursuing health and fighting disease. To admit that the fulfilment of some of our ideals may make the fulfilment of others impossible is to say that the notion of health care delivery is a formal contradiction.

Now let us consider the pursuit of happiness and pancreatic cancer surgery. When I am at work transecting the neck of the pancreas in a patient with pancreatic cancer, I often think ahead to the possibility of anastomotic leak or pancreatic abscess and fistula, and I wonder if the time, effort, and money spent in undertaking this operation, often morbid and frequently futile, would not be better spent on smoking and alcohol cessation programs. What, after all, is the cost of pancreatic cancer resection in relationship to quality-of-life? The answer, or at least a beginning to an answer, comes in seminal work like that from Ljungman and colleagues [2]. There must be some way reasonable men and women can solve the inherent conflicts in caring for the sick, and a large step in resolving the pancreatic cancer cost-effectiveness question is provided in the careful estimate by Ljungman and associates. Their work provides and evaluation of the cost-utility of surgical treatment of patients with pancreatic exocrine and ampullary cancer treated at a large Swedish university hospital between 1998 and 2005 .

Fifteen years have passed since a panel of physicians, health economists, ethicists, and health policy experts recommended that cost-effectiveness analyses should use quality-adjusted life-years (QALYs) as the standard metric for identifying and assigning value to health outcomes $[3,4]$. The Swedish health care system offers many 
advantages in the collection and analysis of the cost-perQALY for pancreatic cancer surgical management. The survival information is clear-cut, the treatment costs are specific and complete; the clinical practice and experience is uniform and represents standards of care. Has medical justice been served?

Most pertinent to the cost-effectiveness debate is that costs were analyzed only for patients in whom total lifetime treatment expenditures were available; the QALY cost for pancreatic cancer surgical treatment was close to 35,000 . In comparison, the QALY cost for renal transplantation is much less at 12,000 . Moreover, the cost of pancreatic cancer treatment is much lower than the lifetime renal dialysis costs per QALY of around $€ 60,000$.

The data and conclusions in the study by Ljungman et al. are pertinent to the U.S. health care crisis and the challenges of implementing the Patient Protection and Affordable Care Act of 2010, President Barack Obama's effort to provide health care to all U.S. citizens. The Affordable Care Act was enacted with provisions that limit the use of cost-per-QALY thresholds in comparativeeffectiveness research.

There is limitation to the power of QALYs as the only benchmark for allocating health care resources, but many countries and the World Health Organization have found that QALYs are better than other measures of health improvement [5]. The study by Ljundgren et al. gives impetus to expanding comparative-effectiveness research and to catalyzing research comparing clinical outcomes in surgery for pancreatic cancer. Cost-effectiveness analysis, sometimes decried as rationing, or as "pulling the plug on grandma," offers an assessment of the added improvement in health outcomes relative to cost. Because there are opportunities to substitute more cost-effective clinical strategies for less cost-effective ones, costs can be lowered without adversely affecting health care. Proscribing the use of comparative effectiveness as a guide to health care policy ignores the inescapable argument that, at some point, difficult choices must be made. And to make those choices, we need more data on cost-effectiveness ratios similar to the astute work that Ljungman and colleagues have delivered. Their work is a major step toward helping to identify and prioritize treatment for pancreatic cancer, and to define the health benefit most people care aboutmore time spent in good health [5].

\section{References}

1. Berlin I (1998) The proper study of mankind. Farrar, Straus and Giroux, New York, p 238

2. Ljungman D, Lundholm K, Hyltander A (2010) Cost-utility estimation of surgical treatment of pancreatic carcinoma aimed at cure. World J Surg. doi:10.1007/s00268-010-0883-8

3. Weinstein MC, Siegel JE, Gold MR et al (1996) Recommendations of the panel on cost-effectiveness in health and medicine. JAMA 276:1253-1258

4. Weinstein MC, Skinner JA (2010) Comparative effectiveness and health care spending-implications for reform. N Engl J Med 362:460-465

5. Neumann PJ, Weinstein MC (2010) Legislating against use of cost-effectiveness information. N Engl J Med 363:1495-1497 